\title{
Criterial Freezing in the syntax of particles
}

\begin{abstract}
In this chapter, it will be shown that in the grammar of German, discourse as well as focus particles are part of the functional structure of the clause, and that in the unmarked case both types of particles take scope exactly where they are merged. Their scope must not be changed in the ongoing derivation. In other words, they are "frozen in place". A challenge comes from those cases in which particles form constituents with sub-sentential phrases such as my bike or in which village, i.e. phrases which do not qualify as scope domains. While co-constituency with sub-sentential phrases is a widely known property of focus particles, corresponding constellations with discourse particles are less widely known and therefore more challenging. Due to this, the focus of the chapter will be on discourse particles. In part 1, I will present what I take to be the current base-line of a syntactic-semantic representation of discourse particles (in German and hopefully beyond). Part 2 develops an account of discourse particles in wh-questions and their dependence on interrogative force. Part 3 shows how discourse particles can directly combine with wh-phrases, and how the movement of phrases that are composed in such a way and their scope properties can be integrated into the account developed in part 2. Importantly, I will show that their scope freezes in a position lower than the position seen in surface structure. This finding defines the goal of our consideration of focus particles. Part 4 integrates focus particles and shows that the analysis gets close to a unified account of focus particles and discourse particles. The perspective and advantage of a unified theory of particles is commented on in section 5 . Section 6 draws some conclusions.
\end{abstract}

Keywords: discourse particle, focus particle, scope, criterial freezing , agreement, illocutionary force, clause type (CT), speech act (SA), question, copy movement

\section{Discourse particles in situ}

Discourse particles (DiPs, in German known as Modalpartikeln or Abtönungspartikeln) make a rather clear semantic contribution to the meaning of a sentence. 1.1 provides an informal semantics of particles that play a role in wh-questions. This is followed by a brief introduction to the way we see the role of particles in the context of variable word order. 1.3 introduces the option of having in the very same clause more than a single DiP. 1.4 turns to the locality of 
licensing a DiP. In 1.5, I will argue that this licensing should be accounted for with the technology of probe-goal agreement.

\subsection{Semantic contribution}

DiPs are geared to certain clause types (declarative, polar interrogative, wh-interrogative, exclamative, imperative etc.) and arise mainly in root clauses. They make a semantic contribution by co-determining the illocutionary force of an utterance (Thurmair 1989; Coniglio 2011). For reasons to be seen shortly, our focus will be on particles that arise in constituent questions. Particles which appear in these questions, but not necessesaily only there, are denn (lit. 'then'), wohl (lit. 'well'), nur/bloß (lit. 'only'/'barely'), schon (lit. 'already') and perhaps some more. Since our primary goal is not to give a detailed account of their contribution to illocutionary meaning, it will suffice to consider the variations in (2) over the particlefree wh-question in (1), and to characterize them descriptively.

(1) Wo wohnt er?

where lives he

'Where does he live?'

(2) a. Wo wohnt er denn?

(2a) means that given a common ground CG between speaker and hearer, where does he live in relation to some aspect of CG; denn is quasi anaphoric to CG. If the CG that relates to the open proposition, here $\lambda \mathrm{x}$, he lives in $\mathrm{x}$, is missing, denn fails to refer, and the question fails pragmatically. This blocks denn-questions out-of-the-blue (see König 1977; Wegener 2002; Grosz 2005; Bayer 2012). ${ }^{1}$

\section{b. Wo wohnt er wohl?}

In assertive clauses, wohl signals uncertainty of the speaker toward the proposition p. According to Zimmermann (2008), the request for an assertion by the

\footnotetext{
1 Assume you chat with someone who has learned in the course of the conversation that you are new in town. Your interlocuter may ask you Wo wohnen Sie denn? Imagine alternatively that you went to the registration office. The employee's job is to write down your data. This person can ask you Wo wohnen Sie? but hardly Wo wohnen Sie denn? The reason is that there is normally no or no presumed relevant CG which denn could point to. Using denn in this situation is, so to say, none of the employee's business.
} 
hearer allows in this case an assertion that is weakened toward a guess or a speculation. While the question remains what it normally is, wohl affects the propositional commitment of the addressee allowing it to be presumably (p) instead of $\mathrm{p}$.

\section{c. Wo wohnt er nur/bloß?}

In (2c), the speaker signals that he/she has so far unsuccessfully tried to find an answer; Obenauer (2004) has aptly dubbed questions of this type I-CAN'T-FINDTHE-VALUE QUESTIONS (CfvQ) (see also Hinterhölzl and Munaro (2015) for pragmatic effects of bewilderment and impatience of the the speaker that nur/blo $\beta$ and also the particle/adverb nun (lit. 'now') give rise to).

\section{d. Wo wird er schon wohnen?}

By using schon, the speaker creates some scale by which the entities (here places) that can replace the variable are ranked according to their plausibility or likelihood of yielding a true answer; schon creates the implicature that few entities are high enough on the scale to make the answer true. This yields a rhetorical question (see Löbner 1990; Meibauer 1994; Bayer and Obenauer 2011; Egg 2012).

\subsection{Word order}

Since DiPs may appear in various linear orders, their surface appearance previously gave rise to the idea that they undergo movement. As expected, no good reason for such movement could be found though. Although they resemble adverbs and are in fact treated as adverbs in many accounts, a surprising finding was that they must not move to the clausal periphery. They can neither move to SpecCP nor can they be extraposed to the post-verbal domain. From today's position, it is quite clear that DiPs arise in a fixed middle-field position, and other constituents move to their left, e.g. by scrambling operations. ${ }^{2}$ Although DiPs contribute to Force, they arise comparatively low in the clause in a fixed position to the left of $v$ P. Weak pronouns must and other topical constituents may move to the left of DiP. ${ }^{3}$

2 See Ormelius-Sandblom (1997).

3 What I say here must be limited to the wh-questions under discussion. The particles ja and wohl, which are discussed in detail in Coniglio (2011:131ff) show slightly different distributions. 
(3) a. *Wann könnte denn er ihn mitgenommen haben? When could DENN he it along-taken have 'When could he have taken it along? (I'm wondering)'

b. *Wann könnte er denn ex ihn mitgenommen haben?

c. Wann könnte er ihn denn ex ihn-mitgenommen haben?

(4) a. Wann könnte denn Otto den Brief gestern ins Büro when could DENN Otto the letter yesterday to office mitgenommen haben?

along-taken have

'When could Otto have yesterday taken the letter to the office? (I'm wondering)'

b. Wann könnte Otto denn Өtt den Brief gestern ins Büro mitgenommen haben?

c. Wann könnte Otto den Brief denn $\theta t t \theta$ den Brief gestern ins Büro mitgenommen haben?

d. Wann könnte Otto den Brief gestern denn Otto den Brief gestern ins Büro mitgenommen haben?

e. Wann könnte Otto den Brief gestern ins Büro denn Otto den Brief gestern ins Büre mitgenommen haben?

The conditions under which elements move to the left of the DiP are not really clear, at least they are less clear than movements across speaker oriented adverbs as discussed in Frey (2007). For the purposes of this chapter, it can be assumed that there is a topic field above the DiP which may host the aboutness topic but perhaps also elements familiar from the preceding discourse. ${ }^{4}$ An important function of the DiP is that it assigns material below its position to the information focus. Notice that in (4a-d) the unmarked phrasal accent is on the PP, i.e. ins BÜRO mitgenommen, while in (4e) the focus domain has shrunk to the verb, i.e. the accent is MITgenommen. ${ }^{5}$ Assuming that the DiP takes a fixed position, the phrase structure appears to be the following.

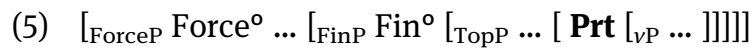

4 The assumption of a TopP is controversial as there is no overt Top-head. We assume it for concreteness. Alternatives are, of course, possible.

5 This fact is a major reason for Egg and Mursell (2017) to propose a direct dependency between DiP and focus. 
We cannot discuss here the relative order of Prt in connection with adverbs in Cinque's (1999) system. For relevant discussion the reader is referred to Coniglio (2011). Unlike most adverbs, DiPs are weak closed-class elements. Much of the inventory of DiPs in German has historically developed out of adverbs or focus particles in a process of grammaticalization. Unlike most adverbs, DiPs can neither be preposed nor extraposed; they are immobile. There is a debate about their X-bar status with rather heterogeneous proposals that range from adverb (assumed without discussion in most semantic work, and assumed with discussion in Manzini 2015), to “deficient” adverb (Cardinaletti 2011; Coniglio 2005, 2011), to head (Bayer 1996, 1999, 2012; Bayer and Obenauer 2011; Munaro and Poletto 2004; Petrova 2017; Struckmeier 2014), and even undefined X-bar status (Meibauer 1994). Assuming head status, a decision that I will further defend below, allows us to be more concrete about (5). ${ }^{6}$ In (6), Prt is the head of a PrtP.

(6) $\left[{ }_{\text {ForceP }}\right.$ Force $^{\circ} \ldots\left[{ }_{\text {FinP }}\right.$ Fin $^{\circ}\left[{ }_{\text {TopP }} \ldots\left[{ }_{\text {PrtP }}\right.\right.$ Prt $\left.\left.\left.\left.^{\circ}\left[{ }_{\nu \mathrm{P}} \ldots\right]\right]\right]\right]\right]$

Weak pronouns and discourse-identified DPs move into the topic field. It is important to notice that they do not move into the specifier or Prt. Weak and topical elements do not associate with Prt. SpecPrtP plays an important role though, but it is reserved for other elements as we will show in detail below.

\subsection{Stacking}

DiPs may co-occur in a clause as long as they are clause-type compatible. Their order is fixed (see Thurmair 1989; Coniglio 2011). In the clause type under consideration, only the order denn > wohl > schon is allowed.

(7) a. Wann könnte Otto denn den Brief wohl gestern schon ins Büro mitgenommen haben?

b. *Wann könnte Otto wohl den Brief denn gestern schon ins Büro mitgenommen haben?

c. *Wann könnte Otto schon den Brief wohl gestern denn ins Büro mitgenommen haben?

6 The top argument against head status has for a long time been that it would inhibit V2. This argument is entirely theory dependent. See Bayer and Obenauer (2011) for a possible solution. Svenonius and Bentzen (2016) suggest that V-movement may not be conventional movement at all. As long as the nature of head movement is still rather unclear, one should meet this argument against head status with reservation. 
Merger of DiPs does not change the basic syntactic category of VP/vP. The reason for this is that DiPs - like other particles too - are syncategorematic heads. In this sense, they do not disrupt the projective spine of the verb, and scrambling out of $\mathrm{VP} / v \mathrm{P}$ does not differ from regular scrambling. Under the assumption of a topic field, (7a) suggests that each of the DiPs is associated with a topic field. However as far as I see, nothing much hinges on this particular solution. The order in which stacked DiPs must appear seems to be a matter of scope although the rationale behind it is so far not clear. One reviewer suspects that one DiP "selects" another particle projection, and that this would be inhibited by scrambling into intermediate positions as seen in (7a). However, selection cannot play a role here for the simple reason that DiPs are optional. Notice that (7a) remains perfectly grammatical if wohl is missing: Wann könnte Otto denn den Brief gestern schon ins Büro mitgenommen haben? If denn selects a wohlP like a verb selects a $\mathrm{PP}$, ungrammaticality would result, contrary to fact.

\subsection{Long-distance dependency and scope}

Notice now that Force c-commands the DiP, but the DiP is arguably not part of ForceP. How can it contribute to Force? Potential solutions in terms of LF movement or formal feature movement must be discarded. As Bayer, Häussler and Bader (2016) point out, question-dependent DiPs may show up in embedded clauses from which wh-movement has taken place. Consider the rhetorical questions in (8).

(8) a. Wo glaubst du, dass man hier nachts um 3 Uhr Where believe you that one here at.night at 3 o'clock schon Benzin bekommt? SCHON gasoline gets

'Where do you believe that one can get gasoline here at 3 o'clock in the night? - Nowhere/hardly anywhere!'

b. \#Wo glaubst du schon, dass man hier nachts um 3 Uhr Benzin bekommt?

These examples make two important points: First, (8a) and (8b) differ in meaning. In (8a), the speaker asks about the places $\mathrm{x}$ such that the addressee believes there is a plausibility ranking of $\mathrm{x}$ according to which one can get gasoline in $\mathrm{x}$ at 3 o'clock in the night. (8b) is syntactically flawless but semantically odd because the speaker asks about the places $\mathrm{x}$ such that there is a plausibility ranking of the addressee's believing that one can get gasoline in $\mathrm{x}$ at 3 o'clock in the night. The oddity comes from the question's pragmatic inappropriateness. If schon would raise to the matrix clause, the seat of illocutionary force, $(8 a)$ and $(8 b)$ would have the same meaning, 
and (8a) would be as awkward as (8b). However, (8a) is not awkward at all. We can conclude from this that the DiP takes scope exactly in the surface position in which we see it. Notice secondly that LF-movement is known to be clause bound. Raising the DiP across the CP-boundary would be highly unexpected. A good theory should try hard to avoid it. In our account, the DiP is a functional head. Functional heads do not move around. In (8a), LF-movement of the DiP toward Force would be transclausal head-movement. But head-movement is known to stay within the CP-phase.

Fortunately, there is an alternative. As has first been suggested in Bayer and Obenauer (2011) (see also Bayer 2012; Bayer, Häussler and Bader 2016 and other researchers who adopted this proposal) DiP may access Force via probe-goal agreement. Under successive cyclic wh-movement as in (8a), the Q-sensitive DiP schon can be probed by an uninterpretable interrogative $\mathrm{C}$ as indicated by the dotted lines in (9). ${ }^{7}$

(9) Wo glaubst du [сР⿴囗d daß man hier ... [PrtP schon $[\nu \mathrm{P} \Theta$ Benzin bekommt $]]]]$ ?

In the absence of long wh-extraction, the interpretation of schon as a DiP is unavailable. Why? Short wh-extraction as seen in (10) and its analysis in (11) leaves the DiP in the CP-phase without offering a chance to probe it from the edge of this CP.

(10) Wer glaubt, dass man hier nachts um $3 \mathrm{Uhr}$ schon Who believes that one here at.night at 3 o'clock already Benzin bekommt? gasoline gets

'Who believes that one can get gasoline here already as early as 3 o'clock in the night?'

(11) Wer glaubt wer [сР daß man hier ... [PrtP schon [ ${ }_{\mathrm{P}}$ Benzin bekommt]]]]? X

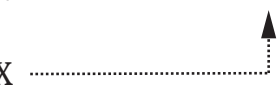

Notice that (10)/(11) is grammatical but only under an interpretation of schon that is irrelevant in the present discussion; schon can only be understood as the temporal adverb 'already', not as the homophonic question-sensitive DiP. As a temporal adverb, schon does not depend in any obvious sense on a particular clause type

7 If $\mathrm{C}$ is $+w h$, it must be uninterpretable. If it were interpretable, selection of the $\mathrm{CP}$ by the verb glauben would lead to a semantic conflict. 
and the illocutionary force of the utterance. It is not a root phenomenon. The syntactic inaccessibility graphically depicted in (11) predicts that the interpretation of schon as a DiP is excluded in this case. ${ }^{8}$

\subsection{Probe/goal agreement}

The next question is how DiPs can contribute to the semantic composition of Force. As we have shown, it does not happen by anything like movement, LF or otherwise. As already said in the previous section, my proposal is that Force is linked to the DiP by probe-goal agreement. This relation enables the left-peripheral representation of illocutionary force to team up in a syntactically defined local domain with features of the DiP that provide information about the speaker's hypothesis about the speech situation and the epistemic state of the addressee. Moving to a more technical level, assume that DiPs have an uninterpretable and unvalued clause-type (CT) feature, here abbreviated as $u \mathrm{Q}[\mathrm{]}$. This is well motivated because DiPs are clause-type sensitive. The DiPs under consideration have this feature among others. At the same time, illocutionary interpretability never resides in the DiP but in a potential Force/CT head which c-commands the DiP. Thus, the DiP is plausibly probed by a CT-head, here Q[ ]. Q[ ] must ultimately be interpretable but may at an intermediate stage of the derivation also be uninterpretable. This is possible in the feature sharing theory of probe/goal agreement proposed in Pesetsky and Torrego (2007), which I adopt here. There is good motivation for splitting up Force in CT and speech act (SA). ${ }^{9}$ Speas and Tenny (2003), Haegeman (2002), Haegeman and Hill (2013),

8 It may be important to know that long wh-extraction as seen in (8)/(9) does not enforce the interpretation as a DiP. The example allows the interpretation of schon as a temporal adverb as well. Thus, (8)/(9) is ambiguous whereas (10)/(11) is unambiguous.

9 Notice that in German, the ASS(ertion)-sensitive DiP ja can co-occur with the Q-sensitive DiP denn in a question if $j a$ belongs to a separate clausal or quasi-clausal domain as in

$$
\begin{aligned}
& \text { Wo hast } d u \quad\left[\mathrm { DP } \text { diesen } \left[\begin{array}{l}
\mathrm{AP} \\
\text { ja }
\end{array}\right.\right. \text { unwahrscheinlich } \\
& \text { Where have you this } \\
& \text { denn gehört? }
\end{aligned}
$$

The speaker who takes responsibility for the adequacy of $j a$ is identical with the speaker who takes responsibility for the adequacy of denn. The AP is quasi by default an "assertive" CT but does not constitute an SA. It must be linked to the speaker of the SA of the root clause (see Hinterhölzl and Krifka 2013; Struckmeier 2014; Viesel 2017). It is the speaker of the root clause who also takes responsibility of the DiP inside AP. 
Miyagawa (2012), Coniglio and Zegrean (2012) and others argue for the syntactic representation in the form of a speech act phrase (SAP). The derivation for licensing a Q-sensitive DiP under cyclic wh-movement runs as in (12), where we symbolize valuation by 1 .

(12) a. $\left[{ }_{v \mathrm{P}}\right.$ wh $\left.\left[{ }_{v \mathrm{P}} \ldots \mathrm{wh} \ldots\right]\right]$

b. [PrtP $\left.\left.\operatorname{Prt}_{u Q[]}\left[{ }_{v \mathrm{P}} \ldots \mathrm{wh} \ldots\right]\right]\right]$

$\Rightarrow$ MERGE Prt $\Rightarrow$

c. [CTP $\left.\mathrm{CT}_{u \mathrm{Q}[}\right]\left[\mathrm{CP}\right.$ wh C [ ${ }_{\mathrm{TP}} \ldots$ [PrtP $\left.\operatorname{Prt}_{u \mathrm{Q}}\right]\left[{ }_{v \mathrm{P}} \ldots\right.$ wh ... ]]]]]

$\Rightarrow$ MOVE $w h \Rightarrow$

d. [СтР $\mathrm{CT}_{u \mathrm{Q}[\mathbf{1}]}\left[{ }_{\mathrm{CP}}\right.$ wh C $\left.\left.\left[{ }_{\mathrm{TP}} \ldots\left[_{\mathrm{PrtP}} \operatorname{Prt}_{u \mathrm{Q}[\mathbf{1}]}\left[{ }_{v \mathrm{P}} \ldots \mathrm{wh} \ldots ..\right]\right]\right]\right]\right]$

$\Rightarrow \mathrm{AGREE} \Rightarrow$ ...

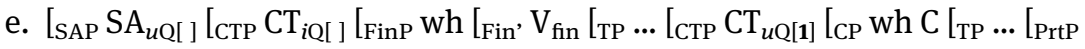
$\operatorname{Prt}_{u \mathrm{Q}[1]}\left[{ }_{v \mathrm{P}} \ldots \mathrm{wh}\right.$... $\left.\left.\left.\left.\left.\left.\left.\left.\left.]\right]\right]\right]\right]\right]\right]\right]\right]\right]$

$\Rightarrow$ AGREE $\Rightarrow$

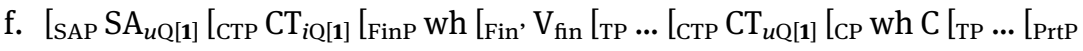
$\operatorname{Prt}_{u \mathrm{Q}[1]}\left[{ }_{v \mathrm{P}} \ldots\right.$ wh ... ] ] ]]]]]]]]]

Agreement between CT and Prt guarantees that the CT is of the type that results from the application of Prt to CT. Provided that (12d) is part of a dependent clause, CT is formally present - consider the notion of an intermediate wh-trace - but nevertheless uninterpretable. ${ }^{10}$ Here, CT agrees with Prt. Further wh-movement leads to (12e). Since wh stops in SpecFinP of the root clause, CT is interpretable. The root clause is not only a proposition but in addition a speech act. By transitivity, agreement between SA and CT guarantees that the root clause is an interrogative speech act enriched with the specific respective "flavors" of Prt that had been exemplified in (2) above. ${ }^{11}$

Importantly, the DiP (Prt) itself does not move. It stays precisely in the pre- $v \mathrm{P}$ position in which it was merged in (12b); in other words, it stays in its irreversible scope position. Thanks to cyclic wh-movement, the root clause's CT/SA can stretch out its fingers to grab the distant DiP without committing a crime against conditions of syntactic locality.

In the next section, we shall provide evidence to the effect that the unmarked pre- $v$ P DiP-position is a CRITERIAL position in which movable

10 This amounts to the claim that a CP which served as a transit for wh-movement is in fact "interrogative". This feature does not do any harm because it is uninterpretable. It is only formally present.

11 Egg and Mursell (2017) develop a theory in which CT/SA probes the $v$ P-related focus domain rather than the DiP. The DiP has an unvalued focus feature which is valued by the interpretable focus feature on $v \mathrm{P}$. Thus, the relation between CT/SA and DiP is at best an indirect relation. It remains to be seen how the CT-dependency of DiPs can follow. 
elements of the right type undergo CRITERIAL FREEZING. This finding will then be taken up again in section 4 to show how, within the theory developed so far, a natural account of focus particles follows almost automatically. At this stage, it will become clear that the syntax of DiPs and the syntax of focus particles rests on the same basic architecture.

\section{Discourse particles ex situ}

One of the classical diagnostics for DiP-status is their immobility (see Thurmair 1989 and arbitrary further work on DiPs). We interpreted this as following from their status as functional heads. According to this analysis, DiPs are on a par with $v, \mathrm{~T}$, Neg, C, Fin, Force etc. There is T-to-C movement, and functional elements occasionally undergo cliticization. In general, however, functional heads stay put; it is lexical heads and not functional heads which move to functional heads. Given that they can be probed from a c-commanding position, DiPs are heads for which there is no prima facie reason to move. As heads, they would not qualify for A'-movement to save the V2-constraint. ${ }^{12}$ Thus, although DiPs are traditionally understood as "idiosyncracies" of German, they turn out to be part of the functional grid on which clause structure rests, and they conform to its rigid order of constituents.

12 As Cardinaletti (2011) points out, DiPs are not contrastable and can therefore not be questioned, and they cannot undergo coordination. It needs to be said that they share these properties with certain higher adverbs like the speaker-oriented adverb leider ('unfortunately'), which are clearly different from DiPs. The issue is too big to be adequately addressed within the confines of this contribution. Nevertheless, an illustrative case is that, as in most OV-languages, many light adverbs in German can be shifted to a post-verbal position.

(i) a. Karl hat drauf verZICHtet

b. Karl hat drauf verZICHtet drauf 'Karl gave up on it.'

Functional heads such as the neg-head nicht never undergo such PF-related movement.

(ii) a. Karl konnte gestern nicht KOMmen

b. `Karl konnte gestern nicht KOMmen nicht

'Yesterday, Karl could not come.'

DiPs do not pattern with light adverbs. They are on a par with bona fide functional heads. 


\subsection{DiPs travelling with $w h$-phrases}

Nevertheless, even this diagnostic seems to have a hole: Unexpectedly, DiPs can be displaced to the left periphery if they co-occur with a wh-phrase, and they can do this even "long distance". 13

13 Contrary to what one reviewer suspects, also other DiPs than those discussed here can participate in this construction, e.g. eigentlich ('actually'). Furthermore, one can also find DiPs that form a constituent with other elements than wh-phrases. Consider the DiP eben (lit. 'even') that occurs in assertive clauses. Instead of the expectable das ist eben ..., both Schiller and Grillparzer use the following stylistically more elaborate and exciting forms.

(i) Das eben ist der Fluch der bösen Tat, daß sie, fortzeugend, this EBEN is the oath (of) the evil deed that it procreatingly immer Böses muß gebären.

always evil must create

J.C. Friedrich Schiller, Wallenstein, 1800.

(ii) Das eben ist der Liebe Zaubermacht, daß sie veredelt, was ihr this EBEN is the love's magic.power that it ennobles what its Hauch berührt, ... breath touches Franz Grillparzer, Sappho, 1819.

The demonstrative pronoun must be emphatically accented, and the preverbal position is by all means occupied by a single constituent. Systematic searches reveal also examples in current ordinary language. Here are two examples with eben and wohl, the latter of which may appear in assertive clauses as well as in questions.

(iii) Manche eben können es nicht

Some EBEN can it not

'Some can just not do it'

https://epetitionen.bundestag.de/petitionen/_2011/_04/_11/Petition_17637/forum/

Beitrag_135586.\$\$.batchsize.10.tab.2.html (26.01.2017)

(iv) Manche wohl können nur kalt sein, obwohl niemand was für some WOHL can only cold be although nobody something for seinen Hauttyp kann.

his skin.type can

'Some can perhaps only be cold although nobody is responsible for his/her type of skin' http://www.akne.org/threads/gro\%C3\%9Fe-poren-auf-der-nase.36463/

It is so far not clear to me why these cases are less frequent and perhaps also less systematic than those in wh-questions. 
(13) a. [An wen denn] könnte er sich [anwen denn] gewandt haben? at who DENN could he REFL turned have 'Who on earth could he have turned to?'

b. [An wen denn] glaubst du, [[an wen denn] dass er sich [an wen denn] gewandt haben könnte]?

'Who on earth do you believe that he could he have turned to?'

As my use of square bracket suggests, $w h P+D i P$ form a constituent. If not, the V2-constraint would be violated. The examples in (13) come across as nothing else but standard cases of wh-movement. No degradation in grammaticality can be noticed. However, if this is true, DiP is really ex situ, outside its rigid scope position we have been arguing for, and in blatant violation of the general semantic requirement that a DiP is like any other operator supposed to take scope over a proposition. Notice that according to standard assumptions, $v \mathrm{P}$ embraces the external argument and therefore represents the minimum of a proposition, in other words, what Chomsky (1986), with binding theory in mind, considers to be a COMPLETE FunCTIONAL COMPLEX.

A second scandal emerges in connection with rigid order. The strict hierarchy that had been diagnosed in the previous section, e.g. denn $>$ wohl $>$ schon in the examples in (7), seems to be disrupted in the well-formed example

(14) [An wen schon] wird er sich damals denn gewandt haben?

'Who on earth will he have turned to after all in those days?' (the answer is obvious)

In (14), the surface order of the DiPs is schon > denn. This order is normally strictly excluded (see (15a)), even across a CP-boundary (see (15b)):

(15) a. * ${ }^{\star}$ An wen $]$ wird er sich schon denn gewand haben?

b. *[An wen] glaubst du schon, dass er sich damals denn gewandt haben wird?

The pertinent questions are (i) how can phrases like $w h+\mathrm{DiP}$ emerge, and (ii) how can one account for the rather alarming exception to word order and scope? My answer will be, as I will shortly show in detail, that in (15), the DiPs schon and denn are "in-situ", i.e. in scope positions, and that these are irreversible. The DiPs have, so to say, been merged into positions where they are frozen from the start. In (14), however, only denn is in a scope position while the DiP schon is part of a complex wh-phrase. The latter particle is "ex-situ". 
This gives reason to believe that the ex-situ DiP may have actually taken scope lower than the in-situ DiP. With this hypothesis, we are on the right track, as I will show. In the following, my account is presented in six steps. The important aspect of the particle's scope variability will be first addressed in (II) and then developed in detail.

\subsection{The core of the account}

(I) DiPs do have a fixed position in the functional cartography of the clause as has been shown in section 1 . This generalization will remain untouched.

(II) However, DiPs can alternatively be merged with a wh-phrase. This operation yields what Bayer and Obenauer (2011) have dubbed 'SMALL PARTICLE PHRASE' (SPrtP). This reminds us of a possibility that plays a role in various accounts of focus particles. In research about focus particles, there is one camp which essentially prevents focus particles from attaching to any non-proposition phrase. The motivation for this is throughout semantic in nature. ${ }^{14}$ There is another camp according to which focus particles may undergo free merger with arbitrary major constituents: DP, PP, CP, next to the standard case $v \mathrm{P} .{ }^{15}$ We will take up the issue in more detail in section 4 . For the time being, let us assume here that the latter camp is right, and that the finding that DiPs can be merged with a wh-phrase adds new syntactic support for this theory. It is important to know that the particle in a SPrtP is not in a scope position, and that, as a consequence, a SPrtP has to undergo movement to a scope position in the sense of (I).

(III) Assuming that a DiP can form a constituent with an arbitrary wh-phrase, what could be the motivation for this? Word order alternations do not arise without reason, as we have learned. Following Bayer and Obenauer (2011), DiPs are heads of type Prt $^{\circ}$ which may undergo merger with a wh$\mathrm{XP}$ and then force $w h$ to raise to their left. The reason for this is that $\mathrm{Prt}^{\circ}$ may bear a feature for EMPHASIS. In fact, all these constructions share a special expressive property of excitement. The wh-phrase in the $w h+P r t$ construction bears distinctive phonetic prominence, and questions with this construction are interpreted as exclaimed constituent questions, i.e.

14 See Jacobs (1983), with a somewhat different orientation Büring and Hartmann (2001), Kleemann-Krämer (2010), and more recently Hole (2015).

15 This view has been defended in Bayer $(1996,1999)$ and in Reis (2005) for German, and in Barbiers (2014) for Dutch. 
questions which are uttered with an enhanced level of excitement by the speaker. Trotzke and Turco (2015) support this impression with experimental data that show a distinct acoustic signature for this construction as compared with a) the non-adjacent position (wh ... Prt ${ }^{\circ}$ ) and b) to the adjacent position of a PP (wh+PP ..., e.g. [Wo bei euch] kann ich heute ... ? 'Where at your place can I ... ?'). In the Trotzke and Turco study, the onset of the wh-word,/vo/, and the following vowel are significantly longer in the SPrtP. As in the study by Niebuhr (2010), the intensifying emphatically pronounced words are not realized with steeper pitch slopes than corresponding non-emphatic words. This suggests the existence of a specific phonetic correlate that distinguishes emphatic fronting from correlates of information structure. ${ }^{16}$ In technical terms, we assume that the derivation of a SPrtP runs as in (16), where 7 is an arbitrarily chosen agreement index. The head $\mathrm{Prt}^{\circ}$ bears an uninterpretable feature of emphasis that is valued and subsequently deleted by a wh-phrase with a corresponding interpretable feature of emphasis.

(16) a. $\operatorname{Prt}^{\circ}{ }_{u \text { Emp [ ] }}$ Wh $_{i \operatorname{Emp}[]}$

b. [wh $\left.{ }_{i \operatorname{Emp~[~]~}}\left[\operatorname{Prt}^{\circ}{ }_{u \text { Emp [ ] }}{ }_{i \mathrm{Emp} \mathrm{[} \mathrm{]}}\right]\right]$

$\Rightarrow \mathrm{MOVE} \Rightarrow$

c. $\left[\mathrm{wh}_{i \mathrm{Emp} \mathrm{[7]}}\left[\mathrm{Prt}^{\mathrm{O}}{ }_{\mathrm{HEmp} \mathrm{[7]}} \mathrm{wh}_{i \mathrm{Emp} \mathrm{[7]}}\right]\right]$

$\Rightarrow \mathrm{AGREE} \Rightarrow$

The interested reader may consult Bayer and Trotzke (2015) for further discussion of this analysis and a remarkable extension that integrates the attachment of multiple DiPs as can be seen in examples like an wen denn wohl schon ('to who DENN WOHL SCHON'), which are by all means part of a single constituent.

16 Although this could not be systematically explored so far, there is a strong impression that SPrtPs need to be fronted and cannot stay in situ in multiple questions. Consider the contrast between (i) and (ii).

(i) An wen denn könnte er sich wann gewandt haben? at who DENN could he REFL when turned have 'Who on earth could he have turned to when?'

(ii) ?^An wen könnte er sich wann denn gewandt haben? at who could he REFL when DENN turned have 'Who could he have turned to when on earth?'

The contrast is reminiscent of Pesetsky's (1987) observations about multiple what-the-hell questions. 
(IV) Given the phrase structure in (6), SPrtP cannot be derived from this structure. Movement of $w h$ to the right of the head of the particle phrase (PrtP) would among other violations violate the ExTENSION CONDITION, see Chomsky (1995), that requires that syntactic operations may extend the tree only at the root. Furthermore, moving away the scope-bearing pre$v \mathrm{P}$ particle would violate scope freezing as assumed throughout, see (I). ${ }^{17}$ Let us therefore keep to the insight that the scope of a DiP that has been merged into a scope position is immune to further derivational manipulation. Thus, an alternative derivation is needed by which the SPrtP is mapped onto the phrase structure in (6).

(V) The alternative is to build SPrtP in a separate workspace WS2 and to add it to the numeration that serves workspace WS1 to build VP, $v \mathrm{P}$ and its structural extensions. SPrtP is first merged in $v \mathrm{P}$. Being a wh-phrase, it needs to undergo

17 Reis (1992) suggests in passing that the DiP may cliticize to the wh-phrase from its base position. This would, however, amount to extraction of the DiP from its otherwise irreversible scope position, and it is unclear why the process of cliticization may target exactly a wh-phrase and nothing else. One reviewer suggests that the assumption of a SPrtP could be unnecessary because the wh-phrase may move through the specifier of the PrtP in the course of which Prt could cliticize to it. The $w h$-phrase could land in SpecPrtP in order to value the uninterpretable Prt-feature $u \mathrm{Q}$ [ ] under Spec-head agreement. Like Reis (1992), this proposal misses the important point that DiPs are functional heads but no clitics. Interestingly, there is one exception: denn has also a clitic form, namely $-n$. As shown in Bayer (2012) and Weiß (2013), $-n$ undergoes Wackernagel-cliticization in various dialects and spoken varieties. Even more interesting is the fact that cliticization to a wh-phrase leads to severe ungrammaticality. Compare the difference between (i), a variant of (2a), and (ii).

Wo wohnt-n der?

where lives $-\mathrm{N}$ he

(ii) ${ }^{\star}$ Wo $-n$ wohnt der? where-N lives he

Apart from this, it would be quite implausible for a trisyllabic element like eigentlich to behave like a clitic. Nevertheless, there are examples like (iii).

(iii) Von wem eigentlich hat er das abgeschrieben?

from who EIGENTLICH has he this copied

'Who did he actually copy this from?'

Thus, we can be sure that cliticization of Prt to the wh-phrase offers no viable alternative to the explanation suggested here. 
A'-movement and is in a first step moved to the phase-edge of $v \mathrm{P}$. In agreement with the copy-theory of movement, the SPrtP leaves a copy behind. As the derivation proceeds, the functional head Prt is merged with $v \mathrm{P}$ and projects a PrtP. Prt is normally an empty head. ${ }^{18}$ This is in full analogy to the merger of an empty C-head in wh-movement constructions. Prt has at this stage the uninterpretable unvalued feature $u$ Prt[ ]. The SPrtP moves into the specifier of PrtP and values $u \operatorname{Prt}[]$. At this point, the particle is de-activated and its scope is frozen. ${ }^{19}$

(VI) The SPrtP is, of course, also a wh-phrase whose wh-feature is still active. It cannot be de-activated before the upper clausal periphery (here SpecFinP) has been reached. Thus, the SPrtP moves out of SpecPrtP again. [Wh+Prt] is a syntactic constituent in which the phonetic occurrence of Prt is pied-piped along with the wh-XP. The corresponding functional head stays and marks the particle's frozen scope. It is important to see that at this stage the Prt of the SPrtP has no core grammatical function any longer. This is in agreement with the classical observation that DiPs are immobile. Their displacement to the left periphery is simply an epiphenomenon of pied piping. (17) gives the derivation (features sometimes suppressed for readability):

(17) a. $[(. ..) \mathrm{V}]$

b. $\left[{ }_{v \mathrm{P}} \ldots \operatorname{SPrtP}(\ldots) \mathrm{V}\right]$

c. $\left[{ }_{v \mathrm{P}} \operatorname{SPrtP}\left[{ }_{v \mathrm{P}} \ldots \operatorname{SPrtP}(\ldots) \mathrm{V}\right]\right]$

$\Rightarrow$ MERGE SPrtP $\Rightarrow$

d. [PrtP $\left.\operatorname{Prt}_{u \operatorname{Prt}[]}\left[{ }_{v \mathrm{P}} \operatorname{SPrtP}\left[{ }_{v \mathrm{P}} \ldots \operatorname{SPrtP}(\ldots) \mathrm{V}\right]\right]\right]$

$\Rightarrow$ MOVE SPrtP $\Rightarrow$

$\Rightarrow$ MERGE Prt $\Rightarrow$

e. $\left[{ }_{\operatorname{PrtP}} \operatorname{SPrtP}_{i \operatorname{Prt}[]}\left[\mathrm{Prt}, \operatorname{Prt}_{u \operatorname{Prt}[]}\left[{ }_{v \mathrm{P}} \operatorname{SPrtP}\left[{ }_{v \mathrm{P}} \ldots \mathrm{SPrtP}(\ldots) \mathrm{V}\right]\right]\right]\right] \Rightarrow \mathrm{AGREE} \Rightarrow$

f. [PrtP $\left.\operatorname{SPrtP}_{i \operatorname{Prt}[9]}\left[\mathrm{Prt} \operatorname{Prt}_{u \operatorname{Prt}[9]}\left[{ }_{v \mathrm{P}} \operatorname{SPrtP}\left[{ }_{v \mathrm{P}} \ldots \mathrm{SPrtP}(\ldots) \mathrm{V}\right]\right]\right]\right]$

18 See however Bayer (forthcoming) and Barbiers (2010; 2014), as well as the brief discussion at the end of this section.

19 Saying that Prt has the uninterpretable unvalued feature $u \operatorname{Prt}[$ ] that gets valued by a SPrtP moving into SpecPrtP is a mechanical consequence of the feature valuation mechanism. Depending on the clause type in which a DiP occurs, the particle has also a "contentive" feature, in the case of interrogatives the feature $u \mathrm{Q}[$ ]. If $u \mathrm{Q}[$ ] is part of the SPrtP, it will become part of the Prt-projection it is attracted to. From there, it will be valued by Force as shown in the derivation in (12). DiPs that attract a $w h$-phrase to their left have in addition the feature $u$ Emp[ ]. This feature gets valued by a wh-phrase that bears an interpretive feature of emphasis. Keeping track of the different features is difficult, and I tried to represent only those which play a role in a certain process. Thanks to one reviewer who asked for clarification.

Peter Culicover (p.c.) asks whether merger of the empty Prt-head could take place with a particular $v \mathrm{P}$ from a series of $v \mathrm{P}$-shells in which the different verbs form a V-cluster. I did not find a way how to trace potential semantic differences. Thus, I assume for the time being that Prt is merged with the upmost $v \mathrm{P}$-shell. 
(17f) is the stage at which the particle of the SPrtP is deactivated and frozen. Due to the concomitant decomposition of SPrtP into Prt and the wh-phrase proper, the semantic problem of scope failure is solved. The DiP has clausal scope despite the formation of a SPrtP. ${ }^{20}$

Further movement raises SPrtP, which is, of course, also a wh-phrase, into SpecFinP etc.

g. [FinP $\operatorname{SPrtP}_{i w h[12]}\left[{ }_{F i n}, \operatorname{Fin}_{u w h[12]} \ldots\right.$ [PrtP $_{\mathrm{SPrtP}_{i w h}[12] ; i \operatorname{Prt}[9]}\left[\mathrm{Prt}, \operatorname{Prt}_{u \operatorname{Prt}[\mathbf{9}}\right]$ $\left.\left.\left.\left[{ }_{v \mathrm{P}} \operatorname{SPrtP}\left[{ }_{v \mathrm{P}} \ldots \mathrm{SPrtP}(\ldots) \mathrm{V}\right]\right]\right]\right]\right]$

This concludes the core of my proposal. We can now see the merits it has. One merit is that the account respects natural constituency as could be observed in movement and observance of the V2-constraint. Another one is that it offers a motivation of the construction. The ex-situ example (13a), An wen denn könnte er sich gewandt haben?, is not synonymous with the in-situ example An wen könnte er sich denn gewandt haben?. The former expresses a degree of exclamativity and excitement of the speaker that is missing in the second one. According to the present account, the examples rest on different derivations on the basis of the same lexical items. A third merit is that it solves the problem of apparently wrong order in a straightforward way. Recall that example (14) is well-formed but shows the linear order schon > denn, which is banned otherwise. The present theory declares the surface order as irrelevant because schon has taken scope below denn before it moved along with the wh-XP wen. Scope freezing is visualized in (18) with $\checkmark$.

(18) ${ }_{\text {FinP }}[$ An wen schon $]$ wird er sich damals $\left[{ }_{\mathrm{PrtP} 1}\right.$ denn $\left[{ }_{\mathrm{PrtP} 2}[\right.$ an wen schon $]$ Prt $\checkmark$ $\left[{ }_{v \mathrm{P}}\right.$... [an wen schon] gewandt haben $\left.\left.\left.]\right]\right]\right]$ ?

Schon is scopally irrelevant in its surface position but relevant in the medial position. In the medial position it takes scope via agreement with the boldfaced functional category Prt, and this position is below the $\mathrm{DiP}$ denn, as it

20 Arguing against this analysis would be like arguing against wh-phrases which are of subpropositional size and move to a position in which they attain scope over a proposition. I know of no linguist who has proposed that which man cannot be a DP because the inherent whoperator does not scope over DPs. 
should be. Thus, the relevant order is exactly the attested one, namely denn > schon.

As one reviewer correctly notes, the transition from (17f) to (17g) is not compatible with the Criterion approach as formulated in Rizzi (2006: 112). According to Rizzi, a phrase meeting a criterion is frozen in place. What is important here is the $a$ in both $a$ phrase and $a$ criterion. The principle as formulated here stops a unique phrase XP with a unique feature $\mathrm{F}$ in some criterial position whose head matches F. No further movement obtains because F has ceased to be active. As we have seen, however, the SPrtP is actually composed of two phrases. It is a whphrase that is immediately dominated by a shell that is headed by a particle. Due to this dominance relation, the SPrtP is at first a particle phrase. As such it is raised to the specifier of the silent Prt-head where it is deactivated. So far, this is exactly what Rizzi (2006) suggests. Since the SPrtP involves next a wh-phrase with an active $w h$-feature, and since this $w h$-feature cannot be de-activated in SpecPrtP, the SPrtP must move on to the left edge of the clause where wh-checking takes place. The only question I see here is why the derivation pied-pipes the SPrtP instead of using sub-extraction of the wh-phase. Although I do not have a watertight answer, the reason seems to be that sub-extraction of the wh-phrase would disrupt the emphatic construction that motivates the formation of a SPrtP in the first place. Apart from the pied-piping issue, the logic of the derivation seems to be completely in line with the Criterion approach and Criterial Freezing. ${ }^{21}$ (19) visualizes the word order and reconstruction consequence of my account.

21 As Abels (2012: 83ff) shows, there are various other cases which argue against an overly rigid understanding of Rizzi's Criterion approach. A well-known example is the variant of (i) in (ii) that has been detected and discussed in Reis and Rosengren (1992).

(i) Stell dir vor, wen Peter besucht hat! imagine REFL Prt who.ACC Peter visited has 'Imagine who Peter visited!'

(ii) Wen stell dir vor, dass Peter besucht hat! who.ACC imagine REFL Prt that Peter visited has

It can be argued that the movement that lifts wen into the root clause is not wh-movement that could interfere with the wh-criterion but rather a form of topicalization of the $w h$-phrase. If so, the case would be analogous to the one under discussion. A detailed discussion of freezing effects and their theoretical accounts would go far beyond the scope of this contribution as the discussions in Müller (2010) and in other contributions to the present volume show. 


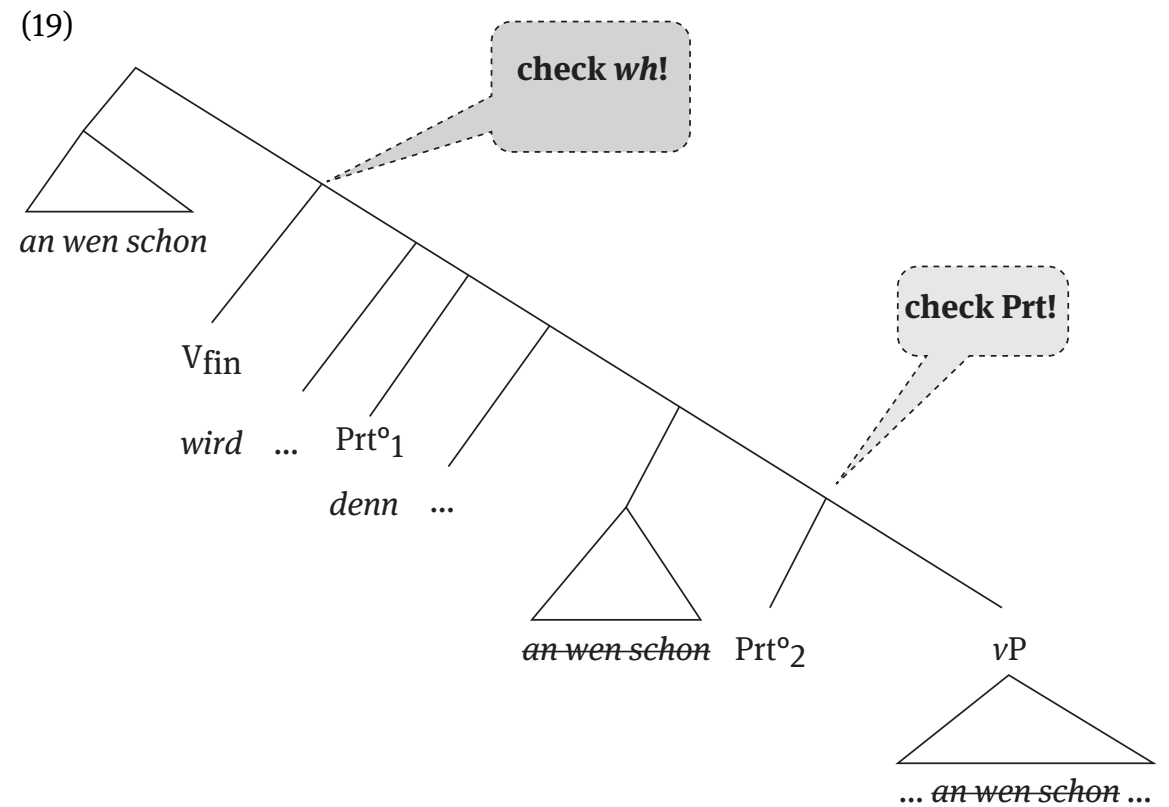

SPrtPs move like wh-phrases, the difference being that there is yet another feature to take care of. If we are right, the head of the SPrtP is Prt. The $w h$-phrase is embedded in SPrtP. Given this dominance relation, it is expected that the SPrtP moves first to a position where it values the functional category $\mathrm{Prt}^{\circ}$, which is in (19) $\mathrm{Prt}^{\circ}{ }_{2}$. From this point onwards, the DiP schon of the SPrtP an wen schon is inactive. The head $\mathrm{Prt}^{\circ}{ }_{1}$ which hosts the DiP denn is irrelevant and would anyway be skipped because the features of schon and denn are distinct. This makes the SPrtP transparent for the whfeature, and it can move on to a destination in which it values the $w h$-feature which for the sake of the present discussion we assume resides in Fin.

The combination of copy movement with the fact that DiPs are optional elements predicts ambiguities. Since Prt is merged optionally, and since SPrtP moves cyclically through SpecCP, SPrtP may value a silent Prt-head either locally or at a distance. Consider (20).

(20) [Vor wem denn] glaubst du, dass sich James Bond schon from who DENN believe you that REF James Bond SCHON fürchten würde?

fear would

'Who do you believe that James Bond would be afraid of?' - Of no one, of course! 
Since the freezing point of the SPrtP may be in the matrix clause or in the embedded clause, an ambiguity is expected. This ambiguity is real as corresponding examples with denn in situ reveal.

(21) a. Vor wem glaubst du, dass sich James Bond denn schon fürchten würde?

b. Vor wem glaubst du denn, dass sich James Bond schon fürchten würde?

The meaning of (21a) is that there is a common ground CG between speaker and hearer such that the speaker asks the hearer rhetorically who James Bond would be afraid of in relation to CG. The meaning of (21b) is that there is a common ground CG between speaker and hearer such that the speaker asks the hearer rhetorically who in the world of the hearer's beliefs James Bond would be afraid of in relation to CG. The difference may be subtle, but our discussion of (8) above has shown that it is likely to be real. The important fact is that (20) embraces both of the readings expressed in (21).

\subsection{Particle doubling}

The account of SPrtPs in terms of a dual structure gives rise to new questions. Since the SPrtP must cycle through a type-corresponding and scope-bearing PrtP, it could in principle be possible that the head of PrtP is not silent but equally spelled out. Barbiers (2010; 2014) finds such data in Dutch focus particle constructions and gives an account for them which is close to what I am proposing here. ${ }^{22}$ One of his examples is (22).

(22) Maar een boek ken ik maar

only one book know I only

'I know only one book.'

Here, [maar een boek] is a constituent which has passed through a particle projection in which the lower particle maar is in its scope position. Searches on the internet could spot many examples of DiP-doubling in which the structure is arguably the same as in (19) with the difference that the head-position $\operatorname{Prt}^{\circ}{ }_{2}$ is

22 If it appears that Dutch has FP doubling while German has DiP doubling, this would be a strange parameter. In fact, I believe, both languages have both. For some discussion see Bayer (forthcoming). However, the issue awaits further research. 
lexically filled with the DiP whose scope we are claiming gets frozen in this position. $^{23}$

(23) a. Warum nur seid ihr nur sooo gehässig?

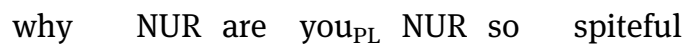

'Why on earth are you so bitchy?'

http://www.purkersdorf-online.at/komm/_da.php?ar=7\&num=02046-00001-00001-

00002-00001-00001-00000-00000-00000-00000 (25.01.2016)

b. Warum nur war er nur so unerreichbar für mich?

why NUR was he NUR so unreachable for me

'Why on earth is he so unreachable for me?'

https://www.wattpad.com/78507062-i-wish-larry-german-au-kapitel-19 (25.01.2016)

c. Wer wohl ist wohl der Typ mit dem Doppelkinn, und

who WOHL is WOHL the guy with the double chin and

der spärlichen Frisur?

the sparse hair

'Who may be the guy with the double chin and the sparse hair?'

http://www.wrestling-infos.de/board/showthread.php?t=25441 (23.01.2016)

d. Vor was denn ist er denn geflüchtet?

from what DENN is he DENN fled

'What did he flee from, I'm wondering'

http://www.trennungsschmerzen.de/verlassen-mit-baby-wer-noch-t604.html (24.01.2016)

e. Wer schon hätte schon Lust gehabt, seine Freunde zu

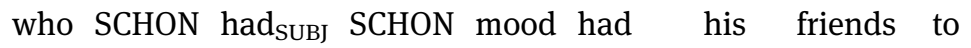
verpfeifen?

squeal-on

'Who after all would have been in the mood to squeal on his friends? (No one!)'

https://books.google.de/books?id=r4QhCwAAQBAJ\&pg = PT1870\&lpg=PT1870\&dq=\%

22wer+schon+h\%C3\%A4tte+schon\%22\&source=bl\&ots=WlLJ9Odk19\&sig=qQwFZxfSv c4qpJc4kee052vyK8U\&hl=de\&sa=X\&ved=0ahUKEwiX8vLkjMDKAhWEGCwKHcqxDnAQ6AEIHzAA\#v=onepage\&q=\%22wer $\% 20$ schon $\% 20 h \% C 3 \% A 4 t t e \% 20$ schon $\% 22 \& \mathrm{f}=$ false (23.01.2013)

23 My thanks to Verena Simmler for running these searches. A detailed discussion of particle doubling is offered in Bayer (forthcoming). One reviewer expects that the second occurrences of the DiPs are different from the stand-alone versions of these particles. While this is a possibility, I believe the two DiPs in the present examples are the same, the second one being the spell-out of the Prt-head that is otherwise empty. 
There is no reason to assume doubling in a semantic sense. The interpretable occurrence of the $\mathrm{DiP}$ is in each case the lower one. The emphatically marked whphrase cycles through the criterial position in which it agrees with the Prt-head before it continues to move on with the $w h$-phrase for wh-checking. The phonetically high occurrence of the DiP in (23a) through (23e) has no semantic significance for the computation of its scope.

\subsection{WYSIWYG is wrong}

This concludes part of my thoughts about the integration of German DiPs into the syntactic framework of minimalist syntax. The important message is that WHAT YOU SEE IS WHAT YOU GET (WYSIWYG) is very likely to be wrong. Once a DiP has teamed up with a wh-phrase, wh-movement superficially obscures the fact that the DiP has been de-activated before the complex phrase has reached its surface position. Thus, a DiP may phonetically appear in a place which is irrelevant for its scope. In the following section, the debate about focus particles will be reconsidered in this light as I believe the present account has a lot to recommend about focus particles as well.

\section{Integrating focus particles}

The syntax of focus particles (FP) like only and even and their correspondents in other languages is up to now highly controversial. There are essentially two camps, the "adverb camp" and the "mixed camp". At least for the study of German, the "adverb camp" owes a lot to the groundbreaking work of Jacobs (1983). Büring and Hartmann (2001) integrated Jacobs' analysis into more recent assumptions about syntactic architecture and the questions of syntaxto-semantics mapping. A core assumption of this approach is that the FP syntactically an adverb - always adjoins to a propositional domain, i.e. essentially a $v \mathrm{P}$ or a $\mathrm{CP}$. The reason is supposed to be that the FP must take propositional scope. ${ }^{24}$ Adjunction to arguments, DP, PP and CPs with an argument role is excluded. The "mixed camp" as represented by Bayer (1996, 1999), Reis

24 Only has an effect on the truth conditions of a sentence such as John only sleeps. In a suitable context it means that all the relevant activities that John is engaged in are sleeping activities, and that other potentially salient activities are excluded. 
(2005), Barbiers (2014) and a few others acknowledges adjunction of FP to the propositional domain $v \mathrm{P}$ but admits also adjunction to other major constituents such as DP, PP and CP. One problem with this account is that adverbs do not freely adjoin to arbitrary constituents. In German, the examples in (24) are ungrammatical.

(24) a. * $[$ Oft [an meine Versicherung]] schreibe ich
often to my insurance write I letters
'I often write letters to my insurance'
b. *[Leider $\quad$ meiner Versicherung] muss ich oft schreiben
unfortunately my
'Unfortunately, I often have to write to my insurance'

These examples would be parsed as inadmissible V3 sentences. ${ }^{25}$

\subsection{Focus particles as functional heads}

According to Bayer (1996, 1999) and the spirit of the account of DiPs in the preceding sections FP is not an adverb but a syncategorematic head which projects either a $v \mathrm{P}$ or some other major constituent, i.e. DP, PP, an argumental CP etc. The result is a particle phrase whose lexical category is identical with the lexical category of the XP that the particle has been merged with. FP+DP, FP+PP etc. are then SPrtPs as they have been motivated in the previous section. The assumption in Bayer $(1996,1999)$ was that the SPrtP which is formally headed by FP is a quantifier. As such it undergoes quantifier raising $(\mathrm{QR})$ to a scope position. It is but a small step to translate this insight into the theory of the Minimalist Program, an issue I will return to below.

English shows that FPs may form smaller constituents than predicted by the adverb theory. The restrictions of adverb adjunction are comparable to those seen in (24). ${ }^{\star}$ Often syntax is what I teach, ${ }^{\star} I$ did not pay enough attention to unfortunately statistics etc. are highly deviant. For FPs this is not the case. The widely known examples in (25) - cf. Taglicht (1984) and Rooth $(1985,1992)$ - do

25 German does have limited access to V3 as Müller (2003; 2005) has shown, but this possibility must not be equated with the more or less unconstrained combination that FP-attachment would imply. 
not only show that FP+DP must be a constituent but also that this constituent targets a propositional domain.

(25) a. We are required to [ ${ }_{v \mathrm{P}}$ study [DP only SYNTAX]] AMBIGUOUS scope of only unfixed

b. We are required to [only ${ }_{{ }_{\nu \mathrm{P}}}$ study SYNTAX]] UNAMBIGUOUS scope of only fixed

c. We are [only ${ }_{\nu \mathrm{P}}$ required to study SYNTAX]] UNAMBIGUOUS scope of only fixed

The scope of the FP in (25a) is unfixed and can be fixed in two ways, either by association with the lower $v \mathrm{P}$ or by association with the higher $v \mathrm{P}$. The former amounts to the reading shown in (25b), the latter to the reading shown in (25c), with clearly different truth conditions. While the "adverb camp" has to admit that (25a) presents an exception, the "mixed camp" has the advantage of explaining why the FP's scope is frozen in (25b,c) and explaining why it is not in (25a). The technical implementation of scoping has been a matter of debate. $^{26}$ Nevertheless, the data in (25) speak in favor of a dual system as proposed by the "mixed camp".

A widely known problem for defenders of the adverb theory of FPs is its incompatibility with word order in German main clauses. Rigid assumption of surface scope forces the adoption of unconventional phrase structure according to which a clause-initial FP has scope over FinP and associates with the adjacent $\mathrm{XP}$ with which it must, of course, not form a constituent.

(26) [FinP Nur [FinP EINER [FinP' hat [те die Polizisten angegriffen]]]]
only ONE $\quad$ has the policemen attacked
'Only ONE person attacked the policemen'

The structure declares the FP nur to be an AdvP that is adjoined to the V2-clause Einer hat die Polizisten angegriffen. Since there is no prosodic break between the FP and the rest of the clause, such examples should be genuine V3 structures. This is strange because examples of this kind do not show the slightest markedness. Another problem is association with focus. The FP must c-command the

26 While Bayer (1996) proposed QR, Kayne (1998) suggested overt movement which is "obliterated" by later steps of remnant movement. With respect to analogous cases of negation, Błaszczak and Gärtner (2005) suggested an account of what they call extended scope taking in terms of a requirement of prosodic continuity. 
focus. If this was all there is to say, (26) could also come out as ${ }^{\star} N u r$ einer hat die POLIZISTEN angegriffen. But this focus association is impossible. Büring and Hartmann (2001: 276) offer a principle which requires FP "to be maximally close to the focus within a given extended projection". But even this proviso is not tenable, as pointed out in Reis (2005: 470 ff.). As long as FP c-commands the focus-bearing XP, FP and focus can sometimes be separated by an intervening non-focal XP. Under the mixed theory and the assumption of FP as a Prt-head that projects a SPrtP, (26) changes to (27).

(27) [FinP [SPrtP Nur EINER [Fin, hat [TP die Polizisten angegriffen]]]]

Here, FP does not c-command the structure below Fin'. So focus association is under tight control. In addition, there is, of course, no reason to assume V3.

Notice next that there is a word order alternative to $(26) /(27)$ in which according to the structure in (28b) the focus would not even be c-commanded by FP.

(28) a. EINER nur hat die Polizisten angegriffen

b. [FinP EINER [FinP nur [Fin, hat [TP $_{\mathrm{TP}}$ die Polizisten angegriffen]]]]

Büring and Hartmann (2001: 240) express doubts about the acceptability of these inverted word orders. However, standard reference grammars of German mention such constructions (cf. Zifonun, Hoffmann and Strecker 1997: 1010), and authentic examples can easily be found. ${ }^{27}$ Notice here also the widely known English example JOHN even understands "Syntactic Structures". For theories which insist

27 (i) Einer nur kann sie erlösen, und dieser Eine ist nur durch die Liebe one only can her redeem and this one is only through the love zu gewinnen

to win

'Only one person can redeem her, and this person can only be won by love' http://dl.bertha-dudde.org/books/TB_DE_118.pdf (22.01.2016)

(ii) Alle anderen gingen in Begleitung und sie nur sollte alleine gehen all others went in company and she only should alone go wie ein Hund ohne Herrn? like $a \quad \operatorname{dog}$ without master 'All the others went in company, and only she should go by herself like a dog without its master' quoted in Bayer and Obenauer (2011). 
on scope taking of the FP in its surface position - and adverb theories tend to fall in this class - cases like (28) present an unsurmountable problem. The FP occupies a scope position from which it should c-command a focus XP. But as (28b) shows, this could work only if c-command is relaxed to m-command. But even if more exceptions and relaxations of this sort are admitted, it remains unclear why examples like (28a) should occur in the first place.

\subsection{Emphatic fronting}

In the present context, it cannot be overlooked that preposing of the focal XP to the left of the FP has essentially the same signature as the ex-situ construction of DiPs that had been under investigation in section 2. Adopting the gist of my earlier work in Bayer (1996, 1999), FPs are not only heads in potential scope positions but possibly also the Prt-head of a SPrtP. In the latter case, the FP may optionally be endowed with an uninterpretable feature for emphasis. If so, the focal XP moves to the specifier of SPrtP (SpecSPrP) and values the uninterpretable emp-feature on FP. Let me propose that in analogy to (16), there are derivations in which FP forms an SPrtP together with a focal non-interrogative XP of type NP, DP, PP etc. We start out with the SPrtP [FP+XP] such as [nur EINER], 'only ONE' or [sogar an die REGIERUNG], 'even to the GOVERNMENT'. If FP is a Prt head which is endowed with the feature $u E m p[]$, the derivation in (29) is expected.

(29) a. $\operatorname{Prt}^{\circ}{ }_{u \text { Emp [ ] }} \mathrm{XP}_{i \text { Emp [ ] }}$

$\Rightarrow \mathrm{MOVE} \Rightarrow$

b. $\left[\mathrm{XP}_{i \mathrm{Emp} \mathrm{[} \mathrm{]}}\left[\mathrm{Prt}^{\circ}{ }_{u \text { Emp [ ] }} \mathrm{XP}{ }_{i \mathrm{Emp} \mathrm{[} \mathrm{]}}\right]\right]$

$\Rightarrow \mathrm{AGREE} \Rightarrow$

c. $\left[\mathrm{XP}_{i \mathrm{Emp} \mathrm{[19]}}\left[\mathrm{Prt}^{\circ}{ }_{u \text { Emp [19] }} \mathrm{XP}{ }_{i \mathrm{Emp} \mathrm{[19]}}\right]\right]$

An Emp-marked FP-constituent in the style of (28) such as [an die REGIERUNG sogar] will then raise like any other SPrtP to the criterial pre- $v \mathrm{P}$ in which it agrees with the standard empty particle head. As in the case of SPrtPs with DiPs, this move freezes the scope of the FP. Nevertheless, the SPrtP can move on to satisfy whatever further feature needs to be satisfied in the upper position of the

(iii) Heute nur ist das noch möglich Today only is this still possible 'Only today is this still possible.' http://www.archive.org/stream/3569904/3569904_djvu.txt (27.01.2016)

Notice that all of these are markedly emphatic expressions in comparison with their counterparts in which the FP precedes the focal XP: nur einer; nur sie; nur heute. 
declarative sentence clause. In standard cases such as (28a), EINER nur hat die Polizisten angegriffen, the SPrtP satisfies the V2-constraint, but this movement has nothing to do with the role that the FP plays. FP has been deactivated before the SPrtP moves on to SpecFinP. If I am right, it would be hard for the adverb theory (a) to make sense of the focus+FP word order and (b) to derive the emphatic reading described above.

A challenging question is why in FP-constructions two word orders are permitted (nur EINER vs. EINER nur) whereas in DiP-constructions only the inverted one is permitted ( $A N$ WEN denn vs. *denn AN WEN). My explanation is that the FPconstruction is based on focus association. Here the FP needs to c-command the focal associate. The focus needs to be "bound" as some researchers used to say. Once the FP, however, carries an Emp-feature, this feature lives its own life, and the focal XP has to raise to its specifier to check the Emp-feature. The situation in DiP-constructions is different because they do not - at least not according to standard assumptions - associate with a focal XP. However, they can have a feature of emphasis. Assuming that Emp can only be checked under fronting, which seems to be strongly supported empirically, DiP-constructions display only one word order, namely the "inverted" one. The order $\mathrm{DiP}+w h$ has no grammatically motivated existence and will not be spelled out after first merge.

\subsection{Long-distance dependency}

In (20) and (21) of section 3, we could demonstrate that a SPrtP, e.g. vor wem denn, can have left a copy in the embedded clause or in the matrix clause. The DiP can have undergone Criterial Freezing in the lower CP or in the higher CP. This explains the ambiguity. Do we find something similar in connection with FPs? Yes, we do. The example in (30), which was provided by an anonymous reviewer, is ambiguous between the two readings displayed in (31).

(30) Nur den PETER hat die Maria gesagt, dass sie liebt. only the Peter.ACC has the Maria said that she loves

(31) a. Die Maria hat nur gesagt, dass sie den PETER liebt the Maria has only said that she the Peter.ACC loves 'Maria only said that she loves PETER (she didn't say anything else)'

b. Die Maria hat gesagt, dass sie nur den PETER liebt The Maria has said that she only the Peter.ACC loves 'Maria said that she loves only PETER (she said she loves nobody but PETER)' 
The reading in (31b) is very easy to get. In the present account, this follows immediately. If there is a PrtP in the embedded CP of (30), the SPrtP nur den PETER cycles through its specifier and takes scope at this point. Thus, the reading in (31b) is derived. Alternatively, the PrtP could also have been in the matrix clause. In this case, the SPrP nur den PETER cycles through the specifier of the matrix PrtP and takes scope at this upper destination. If in (30) nur would be in a WYSIWYG-style scope position as the adverb theory claims, we could derive the reading in (31a) but not the one in (31b), contrary to fact. This is good news for the present account. Another piece of good news is that the grammar of DiPs and the grammar of FPs seem to have substantial properties in common. This conceptual aspect will be taken up again in section 5 .

\subsection{Relative scope}

Let us finally turn to one of the cornerstones of the adverb theory, namely the treatment of relative scope. The adverb theory makes it a point that the FP takes scope in its surface position because (32a) is supposed to show only surface scope and not the reconstructed scope that we see in (32b).
a. Nur seine ${ }_{1}$ Mutter
liebt jeder ${ }_{1}$
ONLY > EVERY only his
Mother-ACC loves everyone-NOM
b. Jeder $_{1}$
liebt nur seine, Mutter
EVERY > ONLY everyone-NOM loves only his Mother-ACC

The argument is that in (32a) the FP nur and its focus-associate seine Mutter cannot form a constituent. If they would, the FP would be reconstructed below the universal quantifier together with the DP seine Mutter, and then show the unattested reading of (32b); cf. Büring and Hartmann (2001: 260ff) and Sternefeld (2006: 336) ${ }^{28}$ There are two arguments which militate against this conclusion, one is empirical, the other

\footnotetext{
28 Hole (2015) adopts the adverb theory but finds a way to circumvent the consequences it has for constituency. He draws a sharp line between exclusive only and evaluative only. If I understand his proposal correctly, the V2-problem is avoided by the assumption that the FP in the topicalized part is always an "ad-focus marker", that it corresponds to the evaluative use of the FP, and that in this use it is "semantically void" (p. 58). I must admit I have a hard time getting a semantic difference between the topicalized and the middle field occurrence of the FP. According to my intuitions, exclusive and evaluative interpretations are equally accessible in both construction types. As I have argued in Bayer (1996), exclusive and evaluative only, previously known as "quantificational" vs. "scalar", derive from the domain in which only is merged and should therefore not be taken as primitives of a semantic theory.
} 
is theoretical. The empirical argument is that in its crude form the judgment is wrong. As soon as the accent on the head noun Mutter is strengthened, not only the DP but also the FP is understood as being in the scope of jeder, exactly as in (32b). Thus, the low reading of the FP cannot be excluded a priori. Of course, the widescope interpretation of nur exists too and appears to be the more accessible one. If so, what does this interpretive difference follow from? My proposal is that it follows from a distinction that Fanselow (2002), Frey (2005) and Fanselow and Lenertová (2011) have identified as FORMAL FRONTING (FF) versus FOCUS FRONTING or CONTRASTIVE FRONTING (CF). FF takes the highest XP from the middle field (which in German may be in TP but in all likelihood also in $v \mathrm{P}$ ) and moves it to SpecFinP, an informationstructurally neutral position in the left periphery. Applied to (32a), this means that the object DP has been scrambled before it was moved to its ultimate destination in SpecFinP. Retaining the assumption that FP is part of the DP, the relevant structure is shown in (33).

(33) ${ }_{v \mathrm{P}}[\mathrm{DP}$ nur seine Mutter] [vP jeder [DP Aur seine Mutter] liebt]]

Given our assumption of a pre- $v \mathrm{P}$ functionally grounded scope position, it is but a small step to (34). In (34), the DP nur seine Mutter is in a criterial position in which its scope is fixed once and for all, as indicated by $\checkmark$.

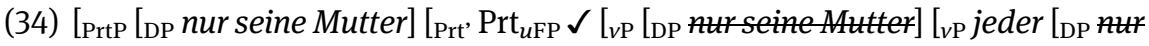
seine Mutter] liebt]]]]

At this point, the DP under discussion can move on to SpecFinP. According to Fanselow, Frey and Lenertová, it is FF-style movement, i.e. essentially an upwards copying of the upper position of $v \mathrm{P}$ in (35) in order to satisfy the V2constraint.

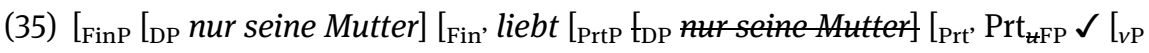
tDP Aur seine Mutter] [ ${ }_{v \mathrm{P}}$ jeder [DP Aur seine Mutter] liebt]]]]]]

PrtP is the relevant phrase in which the FP nur of the SMALL PARTICLE PHRASE (SPrtP) nur seine Mutter values Prt ${ }_{\mathrm{uFP}}$. PrtP is lower than SpecFinP but it is higher than the quantifier jeder. This derives the prominent and unmarked interpretation of (32a), and it does so without the assumption that the FP is an adverb, let alone an adverb which is adjoined to FinP (alias CP). In the same way as in the previous section where we considered discourse particles ex-situ, the particle nur in its function as an FP is not interpreted in its clause-initial position but rather in a much lower position. 
The second observation was that, as a marked option, the FP may still have access to a narrow scope interpretation in relation to the universal quantifier. An important part of this observation was that in this case the fronted DP bears extra heavy stress. Let me understand this as an indication of contrastive fronting (CF). Unlike FF, which may start from a scrambled position, CF starts from $v \mathrm{P}$ or a closely $v \mathrm{P}$-related focus position. Assuming that the anti-focused quantifier jeder is in a higher position, the relevant representation is as in (36).

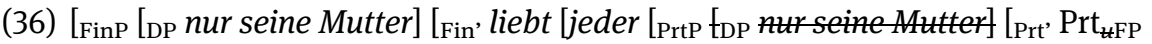
$\checkmark\left[{ }_{\nu \mathrm{P}}\left[{ }_{\nu \mathrm{P}}\right.\right.$ jeder $\mathrm{fDP}_{\mathrm{D}}$ aur seine Mutter] liebt]]]]]]]

The checking station for nur remains exactly the same as in (36). The difference is simply that jeder is in a slightly higher position due to the fact that the SPrtP nur seine Mutter has not been scrambled across jeder. CF is a marked option. Nevertheless it is a possibility. It gives rise to the reading according to which in spite of its linear order nur is interpreted in the scope of jeder.

Essentially, the same point is made in Smeets and Wagner (2016). These authors argue on the basis of Dutch and German examples for an analysis which allows the FP to reconstruct below a quantifier or below an adverb. While Büring and Hartmann (2001) propose a theory by which the FP is a one-place propositional operator that adjoins to VP or an extension of it but never to an argument, Smeets and Wagner propose that the FP only "takes two syntactic arguments, a constituent that corresponds to or at least contains its semantic focus ("Focus Constituent"), and a second constituent ("Remnant Constituent"), whose denotation has to compose with that of the first to form a proposition". This is nothing new, of course. No semantic account of FP can escape the distinction between focus, the XP that the FP associates with, and scope, the domain which provides the open proposition $\lambda \mathrm{x} p(\mathrm{x})$ against which the truth value can be computed. According to the present account as well as to Smeets and Wagner (2016), it is natural that this elementary distinction is reflected in syntactic structure.

A related case in point is scope inversion which is associated with the typical rise-fall contour that Büring (1997) calls "topic accent" (/) as followed by a "focus accent" $(\backslash)$ as in /ALL that glitters is NOT $\mid$ gold. Here, the quantifier is in the scope of negation. The reading is "it is not the case that everything glittering is gold". As pointed out by Reis (2005: 478), scope inversion holds in constructions with FP. Consider (37).

/Nur FLEISCH aß NIE $\mid$ mand

NEG > ONLY only meat ate no.one

'For nobody it was true that he/she ate nothing but meat' 
Büring and Hartmann (2001) refer to this example in their footnote 21 with the comment that "even with this intonational pattern" they would "fail to get an inverted reading". According to my own intuitions, this is surprising because the scope inversion interpretation which they deny here is quasi the only reading that I can get. If my judgment is on the right track, however, nur in (37) cannot be interpreted in its surface position, and the assumption of the SPrtP nur Fleisch becomes unavoidable.

\subsection{A glimpse at negation}

With respect to negation in English, Sternefeld (2006) claims to have detected a related problem by which surface constituency appears to be in disagreement with semantic interpretation. His example is given in (38). The preferred relative scope of the logical operators of negation, modality and quantification appears in (39).

(38) Not every boy can be above average height

(39) $\neg(\diamond(\forall x(x \in$ Ilboyll $\wedge x$ is above average height $)))$

From the LF in (39) it is inferred that not every boy cannot be a constituent, and that in (38) not is in fact adjoined to IP as shown in (40).

(40) [IP not [IP [DP every boy $]_{1}\left[{ }_{\mathrm{I}}\right.$ can [vP $_{1}$ be above average height]]]]

The PF by which not appears in the highest position is thought to be a direct window into the semantic representation. The disturbing fact is, however, that the syntax of negation in English is in disagreement with this proposal. We get examples like Jim didn't wash my car or Jim hadn't heard anything like that before but not *Not Jim washed/did wash my car or *Not Jim had heard anything like that before. Examples like Not Jim but Tom washed my car or Not Jim washed my car but Tom are special cases of so-called "term negation" and seem to have relatively little to do with sentence negation. Apart from this, not as a pre-IP propositional operator seems to be inexistent in English. On the other hand, natural constituency suggests that not and every boy ARE in fact part of one and the same DP [not every boy]. Thus, there seems to be disagreement between the syntax and the semantics of (38). How can this disagreement be resolved? The analysis that comes to mind in the context of the theory developed so far is obvious. Assume that there is an invariant and functionally determined representation of clausal 
negation in the sense of the head of a NegP. Next to NegP there is the possibility of building smaller phrases which are likewise headed by Neg but in which Neg cannot be interpreted as a clausal operator. Given that examples like (38) are specimens of sentence negation, not every boy, not all the girls, not too many kids, not even half of the voters etc. appear to be small NegPs which need to associate with a Neg-head that has propositional scope. We can assume they are built in a separate workspace and are then merged wherever they belong thematically in the VP of the sentence under construction. From inside VP, the small NegP (let's call it SNegP) not every boy will raise to the specifier of clausal negation. Here it is in a typical spechead agreement configuration, and as a consequence its scope gets frozen. Since the SNegP continues to be a DP that needs to check its nominative Case, it will move on to SpecIP/SpecTP essentially pied-piping the subconstituent not along. If so, the scope position of not is not at all what we see at the PF-side of the grammar. Its PF-appearance is rather a somewhat misleading epiphenomenon of natural constituency and pied piping. My tentative proposal for the syntactic derivation of (38) is outlined in (41).

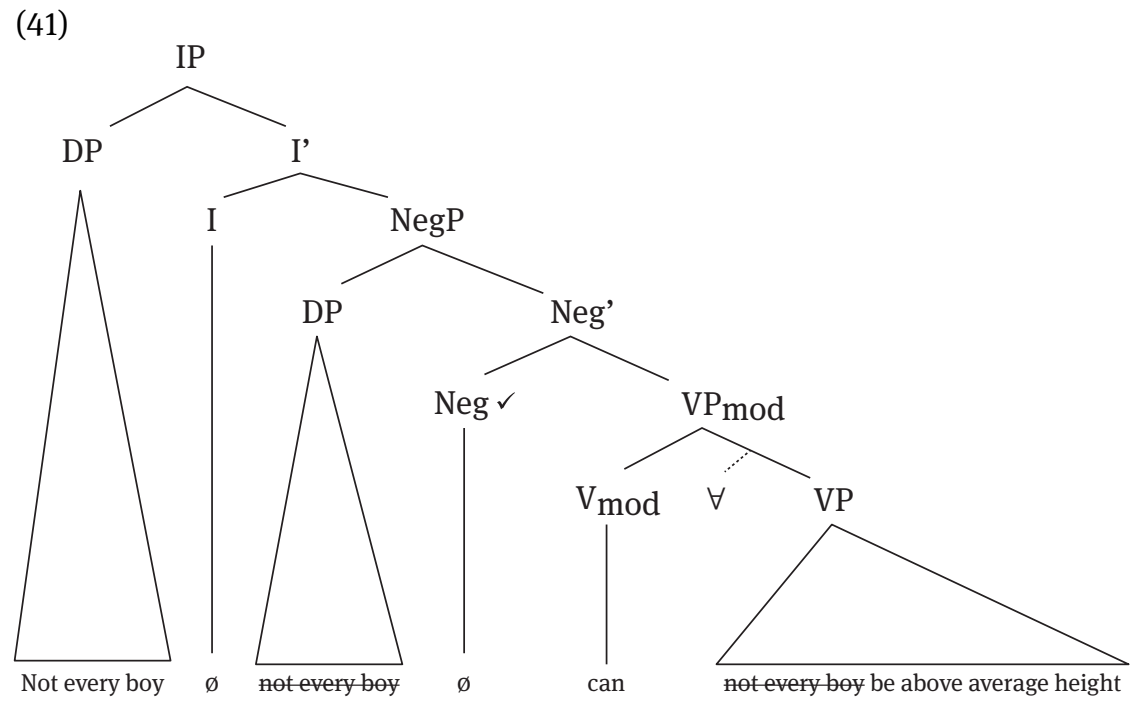

QR is indicated by $\forall$ for concreteness, but this is not of interest here. What is of interest is the scope of negation. The checking site of the Neg-head of the SNegP not every boy is signaled by $\checkmark$. This is the freezing point of negation. Beyond this freezing point, not is inactive. Movement to SpecIP clearly has nothing to do with 
negation. We see that a complex phrase is "decomposed" in the course of the derivation by moving to designated functional positions. The phrase moves to as many functional positions as are necessary to satisfy its relevant features. This has the consequence that what we ultimately see is not what we get. We get much more than what meets the eye.

I am sure that many questions remain but a more thorough treatment would fall outside the scope of this article. My goal was rather to indicate that my analysis of particles, DiPs as well as FPs, may have relevance for domains of grammar that are normally not associated with the grammar of particles.

\subsection{WYSIWYG is wrong again}

We started the section on focus particles with a sketch of the opposition between the so-called "adverb camp" and the so-called "mixed camp". What I proposed here is totally incompatible with the assumptions of the former. However, it is also only weakly compatible with the latter. The reason is that I assume FPs as well as the negator to be functional heads throughout. FPs as well as DiPs are cornerstones of the functional skeleton that builds clause structure, along with T, C, Neg, Asp and other functional categories. The theory is "mixed" only in the sense that not every occurrence of a particle is necessarily in its scope position. Those occurrences in which it is not, fall under the notion of "small particle phrase". These phrases have a feature if not more by which they must undergo movement to a valuation position. In this way, the SPrtPs will pass through "big particle phrases" in which they undergo agreement with the particle and value its corresponding feature. This is the essence of a very simple story which, however, does justice to the grammar of FPs and maybe also to the grammar of negation. WYSIWYG theories turn out to be on the wrong track.

\section{Toward a unified account}

In the history of modern linguistics, FPs and DiPs have by and large been dealt with as two completely separate phenomena and therefore also separate research topics. A plausible reason is certainly that FPs occur virtually in all languages whereas DiPs were only identified in German, Dutch and closely related languages. DiPs were seen as a quirk of West-Germanic. This view has become untenable as more and more languages were found in which closer inspection reveals the existence and the 
functioning of DiPs. ${ }^{29}$ With respect to German, the separation of DiPs and FPs was always a conceptual problem because of the lexical overlap of the two domains; nur, bloß, auch and various others participate in both domains. As Hentschel (1986) and many others have shown, the current inventory of DiPs in German has developed out of lexical categories which mostly continue to exist as such. If so, one is not surprised to see DiPs developing out of FPs, and both DiPs and FPs sharing various properties. The present study has identified some of them. The more remarkable ones are that (i) both appear to be functional heads, (ii) both project next to "big" PrtP also "small" PrtPs, (iii) both show in small PrtPs the phenomenon of emphatic fronting, (iv) small PrtPs move to the specifier of a big PrtP in which their scope is frozen even if movement to further checking sites may still be and in fact often is a possibility but then for independent purposes, (v) both show the phenomenon of particle doubling, albeit, as the contrast between Dutch and German shows, not in the same frequency in each of these languages and (vi) both conform to the architecture that Rizzi (1991/1996) has identified as the configuration of CRITERIAL checking and freezing. This collection of common properties cannot be accidental. It looks very much like the reflex of a unitary system. The irreducible differences between DiPs and FPs are that (a) DiPs are clause type and illocution dependent whereas FPs are by and large clause type and illocution independent ${ }^{30}$ and (b) FPs create an operator/variable relation that is not found in DiPs. ${ }^{31}$ Another question is why FPs occur in all languages and can mostly be translated easily whereas DiPs are much less uniformly distributed and can often not be transferred from one language into another as, for instance, Schubiger (1965) has shown for English and German. Nevertheless, the convergence between DiPs and FPs that the present analysis has revealed should be seen as a step in the right direction.

29 See various contributions in Bayer, Hinterhölzl and Trotzke. eds (2015), Bayer and Struckmeier. eds. (2017), vol. 28 of The Linguistic Review, edited by Biberauer and Sheehan and vol 68 of Studia Linguistica. There is also highly relevant work on Bangla in Dasgupta (1980, 1987, 2005); see also Bayer and Dasgupta (2016) on the Bangla DiP je that is homophonous with one of the complementizers of the language.

30 Not completely though. While only/nur or also/auch are fine in imperatives, even/sogar are not.

(i) Give me only/also/*even beer!

(ii) Gib mir nur/auch/*sogar Bier!

The pragmatic reason for this difference is obviously related to the fact that even/sogar implicates that beer is the least likely substance that I desire, and that this leads to a Gricean clash with the imperative, which is understood as "make it true that I have beer". The conflict does not emerge when also/auch is used because the "least likely" part is missing here.

31 For focus association of DiPs see, however, Egg and Mursell (2017). 


\section{Conclusions}

Attributing functional head status to particles, DiPs as well as FPs, opens an avenue of research that puts these elements right into core syntax. Particles occupy fixed functional positions in clause structure. These Prt positions have been identified as criterial positions in analogy to criterial positions that are familiar from the work of Rizzi (1991/1996) and Haegeman (1995). Particles can alternatively be merged with smaller phrases such as DPs, PPs etc. The scope of these Small Particle Phrases (SPrtP) is unfixed as long as the SPrtP is not in the context of a clause structure that admits the particle as a semantically fully interpretable element. The feature of the particle is active until the SPrtP has reached a matching Criterial position. It is deactivated once SPrtP passes through the specifier of a matching criterial head. The syntax of particles - DiPs as well as FPs - echoes structures and processes that are familiar from more widely studied domains of grammar, especially wh-movement. No construction-specific stipulations have to be added. The differences between different types of SPrtPs follow from the grammatical role that emphasis plays in SPrtP-internal fronting operations.

Let me hasten to say that the theoretical interpretation of the facts we have reached here corresponds closely to the claims that have been forwarded in Bayer (1996). The difference between this approach and the current one resides in technological differences between GB and Minimalism. In GB, SPrtPs were forced to be QR-moved to a scope position. In Minimalism, they can be assumed to raise to the specifier of a functional projection for feature valuation. Apart from this, many of the insights and generalizations remain the same.

Acknowledgments: This research was supported by DFG grant BA 1178/9-1. The quality of this chapter has greatly benefitted from written comments by the editors, by Peter Culicover and by two anonymous reviewers. Thanks also to Sjef Barbiers, Joachim Jacobs, Gereon Müller, Luigi Rizzi, Michael Rochemont, Martin Salzmann, Yvonne Viesel and Michael Wagner. Remaining shortcomings are in my own responsibility.

\section{References}

Abels, Klaus 2012. Phases: An essay on cyclicity in syntax. Berlin: De Gruyter.

Barbiers, Sjef. 2010. Focus particle doubling. In C. Jan-Wouter Zwart \& Mark de Vries (eds.), Structure preserved. Studies in syntax for Jan Koster (Linguistics Today 164), 21-30. Amsterdam \& Philadelphia: John Benjamins 
Barbiers, Sjef. 2014. Syntactic doubling and deletion as a source of variation. In M. Carme Picallo (ed.), Linguistic variation in the Minimalist Framework, 197-223. Oxford: Oxford University Press.

Bayer, Josef. 1996. Directionality and logical form: On the Scope of focusing particles and wh-insitu. Dordrecht: Kluwer.

Bayer, Josef. 1999. Bound focus in German or how can association with focus be achieved without going semantically astray? In Georges Rebushi \& Laurice Tuller (eds.), The grammar of focus, 55-82. Amsterdam: John Benjamins.

Bayer, Josef. 2012. From modal particle to interrogative marker: a study of German denn. In Laura Brugè, Anna Cardinaletti, Giuliana Giusti, Nicola Munaro \& Cecilia Poletto (eds.), Functional heads. The cartography of syntactic structures (vol.7.), 13-28. Oxford: Oxford University Press.

Bayer, Josef. forthcoming. Why doubling discourse particles? Festschrift for Rita Manzini. Bayer, Josef \& Probal Dasgupta. 2016. Emphatic Topicalization and the structure of the left periphery: Evidence from German and Bangla. Syntax 19. 309-353.

Bayer, Josef, Jana Häussler \& Markus Bader. 2016. A new diagnostic for cyclic wh-movement. Discourse particles in German questions. Linguistic Inquiry 47. 591-629.

Bayer. Josef \& Hans-Georg Obenauer. 2011. Discourse particles, clause structure, and question types. The Linguistic Review 28. 449-491.

Bayer, Josef \& Andreas Trotzke. 2015. The derivation and interpretation of left peripheral discourse particles. In Josef Bayer, Roland Hinterhölzl \& Andreas Trotzke (eds.), Discourseoriented syntax, 13-40. Amsterdam: John Benjamins.

Bayer, Josef \& Volker Struckmeier (eds.). 2017. Discourse particles: Formal approaches to their syntax and semantics (Linguistische Arbeiten 564). Berlin: De Gruyter Mouton.

Błaszczak, Joanna \& Hans-Martin Gärtner. 2005. Intonational phrasing, discontinuity, and the scope of negation. Syntax 8. 1-22.

Büring, Daniel. 1997. The great scope inversion conspiracy. Linguistics and Philosophy 20. 175-194.

Büring, Daniel \& Katharina Hartmann. 2001. The syntax and semantics of focus-sensitive particles in German. Natural Language \& Linguistic Theory 19. 229-281.

Cardinaletti, Anna. 2011. German and Italian modal particles and clause structure. The Linguistic Review 28. 493-531.

Chomsky, Noam. 1986. Knowledge of language: its nature, origin and use. New York: Praeger.

Chomsky, Noam. 1995. The Minimalist Program. Cambridge, MA: MIT Press.

Cinque, Guglielmo. 1999. Adverbs and functional heads: A cross-linguistic perspective. Oxford Studies in Comparative Syntax. Oxford: Oxford University Press.

Coniglio, Marco. 2005. Deutsche Modalpartikeln: eine syntaktische Analyse. Venezia: Università Ca' Foscari Venezia Diplomarbeit.

Coniglio, Marco. 2011. Die Syntax der deutschen Modalpartikeln: Ihre Distribution und Lizensierung in Haupt- und Nebensätzen. Berlin: Akademie-Verlag.

Coniglio, Marco \& lulia Zegrean. 2012. Splitting up force: evidence from discourse particles. In Lobke Aelbrecht, Liliane Haegeman \& Rachel Nye (eds.), Main clause phenomena. New horizons, 229-255. Amsterdam: John Benjamins.

Dasgupta, Probal. 1980. Questions and relative and complement clauses in a Bangla grammar. New York: New York University dissertation.

Dasgupta, Probal. 1987. Sentence particles in Bangla. In Elena Bashir, Madhav M. Deshpande \& Peter E. Hook (eds.), Selected Papers from SALA 7, 49-75. Bloomington: Indiana University Linguistics Club. 
Dasgupta, Probal. 2005. Q-baa and Bangla clause structure. In Rajendra Singh \& Tanmoy Bhattacharya (eds.), The yearbook of South Asian languages and linguistics 2005, 45-81. Berlin \& New York: Mouton de Gruyter.

Egg, Markus. 2012. Discourse particles at the semantics-pragmatics interface. In Werner Abraham \& Elisabeth Leiss (eds.), Modality and theory of mind elements across languages, 297-333. Berlin: Mouton de Gruyter.

Egg, Markus \& Johannes Mursell. 2017. The syntax and semantics of discourse particles. In Josef Bayer \& Volker Struckmeier (eds.), Discourse particles: formal approaches to their syntax and semantics (Linguistische Arbeiten 564), 15-48. Berlin: Mouton de Gruyter.

Fanselow, Gisbert. 2002. Quirky subjects and other specifiers. In Ingrid Kaufmann \& Barbara Stiebels (eds.), More than words, 227-250. Berlin: Akademie Verlag.

Fanselow, Gisbert \& Denisa Lenertová. 2011. Left peripheral focus: mismatches between syntax and information structure. Natural Language \& Linguistic Theory 29. 169-209.

Frey, Werner. 2005. Zur Syntax der linken Peripherie im Deutschen. Deutsche Syntax: Empirie und Theorie 46. 147-171.

Frey, Werner. 2007. Some contextual effects of aboutness topics in German. In Andreas Späth (ed.), Interfaces and interface conditions, 329-348. Berlin: Mouton de Gruyter.

Grosz, Patrick. 2005. "Dn" in Viennese German. The syntax of a clitic version of the discourse particle "denn". Vienna: University of Vienna Diplomarbeit.

Haegeman, Liliane. 1995. The syntax of negation. Cambridge: Cambridge University Press. Haegeman, Liliane. 2002. Anchoring to speaker, adverbial clauses and the structure of CP. Georgetown University Working Papers in Theoretical Linguistics 2. 117-180.

Haegeman, Liliane \& Virginia Hill. 2013. The syntacticization of discourse. In Raffaella Folli, Christina Sevdali \& Robert Truswell (eds.), Syntax and its limits, 370-390. Oxford: Oxford University Press.

Hentschel, Elke. 1986. Funktion und Geschichte deutscher Partikeln. „Ja“, „doch“, „halt“ und „eben“. Tübingen: Niemeyer.

Hinterhölzl, Roland \& Manfred Krifka. 2013. Modal particles in adverbial and adnominal clauses. Università di Venezia, Ca'Foscari and Humboldt-Universität zu Berlin manuscript.

Hinterhölzl, Roland \& Nicola Munaro. 2015. On the interpretation of modal particles in nonassertive speech acts in German and Bellunese. In Josef Bayer, Roland Hinterhölzl \& Andreas Trotzke (eds), Discourse-oriented syntax (Linguistics Today 226), 41-70. Amsterdam: John Benjamins.

Hole, Daniel. 2015. A distributed syntax for evaluative 'only' sentences. Zeitschrift für Sprachwissenschaft 34. 43-77.

Jacobs, Joachim. 1983. Fokus und Skalen. Tübingen: Niemeyer.

Kayne, Richard S. 1998. Overt vs. covert movement. Syntax 1 (2). 128-191.

Kleemann-Krämer, Anja. 2010. On apparent NP-internal focus particles in German. The Journal of Comparative Germanic Linguistics 13. 1-29

König, Ekkehard. 1977. Modalpartikeln in Fragesätzen. In Harald Weydt (ed.), Aspekte der Modalpartikeln, 115-130. Tübingen: Niemeyer.

Löbner, Sebastian. 1990. Wahr neben falsch. Duale Operatoren als die Quantoren natürlicher Sprache. Tübingen: Niemeyer.

Manzini, Rita M. 2015. Italian adverbs and discourse particles: between recategorization and ambiguity. In Josef Bayer, Roland Hinterhölzl \& Andreas Trotzke (eds.), Discourse-oriented syntax, 93-120. Amsterdam: John Benjamins. 
Meibauer, Jörg. 1994. Modaler Kontrast und konzeptuelle Verschiebung: Studien zur Syntax und Semantik deutscher Modalpartikeln (Linguistische Arbeiten 314). Tübingen: Niemeyer.

Miyagawa, Shigeru. 2012. Agreements that occur mainly in the main clause. In Lobke Aelbrecht, Liliane Haegeman \& Rachel Nye (eds.), Main clause phenomena. New horizons, 79-111. Amsterdam: John Benjamins.

Müller, Gereon. 2010. On deriving CED effects from the PIC. Linguistic Inquiry 41. 35-82.

Müller, Stefan. 2003. Mehrfache Vorfeldbesetzung. Deutsche Sprache 31. 29-62.

Müller, Stefan. 2005. Zur Analyse der scheinbar mehrfachen Vorfeldbesetzung. Linguistische Berichte 203. 29-62.

Munaro, Nicola \& Cecilia Poletto. 2004. Sentential particles and clausal typing in the Veneto Dialects. In Benjamin Shaer, Werner Frey \& Claudia Maienborn (eds.), Proceedings of the Dislocated Elements Workshop, ZAS Berlin, November 2003 (ZAS Papers in Linguistics 35, Bd. 2), 375-397. Berlin: ZAS.

Niebuhr, Oliver. 2010. On the phonetics of intensifying emphasis in German. Phonetica 67. 170-198.

Obenauer, Hans-Georg. 2004. Nonstandard wh-questions and alternative checkers in Pagotto. In Horst Lohnstein \& Susanne Trissler (eds.), The syntax and semantics of the left periphery, 343-383. Berlin \& New York: Mouton de Gruyter.

Ormelius-Sandblom, Elisabet. 1997. Die Modalpartikeln „ja“, „doch“ und „schon“. Zu ihrer Syntax, Semantik und Pragmatik. Lund: Almqvist \& Wiksell International.

Pesetsky, David. 1987. Wh-in-situ: movement and unselective binding. In Eric Reuland \& Alice ter Meulen (eds.), The representation of (in)definiteness, 98-129. Cambridge, MA: MIT Press.

Pesetsky, David \& Esther Torrego. 2007. The syntax of valuation and the interpretability of features. In Simin Karimi, Vida Samiian \& Wendy K. Wilkins (eds.), Phrasal and clausal architecture: syntactic derivation and interpretation, 262-294. Amsterdam: John Benjamins.

Petrova, Svetlana. 2017. On the status and the interpretation of the left-peripheral sentence particles inu and ia in Old High German. In Josef Bayer \& Volker Struckmeier (eds.), Discourse particles: formal approaches to their syntax and semantics. (Linguistische Arbeiten 564), 304-331. Berlin: De Gruyter Mouton.

Reis, Marga. 1992. The category of invariant alles in wh-clauses: On syntactic quantifiers vs. quantifying particles in German. In Rosemarie A. Tracy (ed.), Who climbs the grammar tree, 465-492. Tübingen: Niemeyer.

Reis, Marga. 2005. On the syntax of so-called focus particles in German - A reply to Büring and Hartmann 2001. Natural Language \& Linguistic Theory 23. 459-483.

Reis, Marga \& Inger Rosengren. 1992. What do wh-imperatives tell us about wh-movement. Natural Language \& Linguistic Theory 10 (1). 79-118.

Rizzi, Luigi. 1991/1996. Residual verb second and the Wh-Criterion. In Adriana Belletti \& Luigi Rizzi (eds.), Parameters and functional heads vol 2, 63-90. New York: Oxford University Press.

Rizzi, Luigi. 2006. On the form of chains: Criterial positions and ECP effects. In Lisa Lai-Shen Cheng \& Norbert Corver (eds.), Wh-movement: Moving on, 97-134. Cambridge, MA: MIT Press.

Rooth, Mats. 1985. Association with focus. Amherst, MA: University of Massachusetts dissertation.

Rooth, Mats. 1992. A theory of focus interpretation. Natural Language Semantics 1. 75-116. 
Schubiger, Maria. 1965. English intonation and German modal particles - a comparative study. Phonetica 12. 65-84.

Smeets, Liz \& Michael Wagner. 2016. The syntax of focus association in German/Dutch: evidence from scope reconstruction. Poster presented at the 39th Generative Linguistics in the Old World (GLOW), Göttingen. 5-8 April. https://www.uni-goettingen.de/en/thursday0704/533636.html (accessed 8 June 2017).

Speas, Maggie \& Carol Tenny. 2003. Configurational properties of point of view roles. In AnnaMaria di Sciullo (ed.), Asymmetry in grammar, 315-344. Amsterdam: John Benjamins.

Sternefeld, Wolfgang. 2006. Syntax. Eine morphologisch motivierte generative Beschreibung des Deutschen. Band 1. Tübingen: Stauffenburg.

Struckmeier, Volker. 2014. 'Ja doch wohl' C? Modal particles in German as C-related elements. Studia Linguistica 68 (1). 16-48.

Svenonius, Peter \& Kristine Bentzen. 2016. There is syntactic head movement, but it isn't movement. Pre-CGSW Invited Talk, Stellenbosch, 1-3 December.

Taglicht, Joseph. 1984. Message and emphasis: on focus and scope in English. London: Longman.

Thurmair, Maria. 1989. Modalpartikeln und ihre Kombinationen. Tübingen: Niemeyer.

Trotzke, Andreas \& Giuseppina Turco. 2015. The grammatical reflexes of emphasis: evidence from German wh-questions. Lingua 168. 37-56.

Viesel, Yvonne. 2017. Discourse particles 'embedded': German ja in APs. In Josef Bayer \& Volker Struckmeier (eds.), Discourse particles - formal approaches to their syntax and semantics, 173-202. Berlin: Mouton de Gruyter.

Wegener, Heide. 2002. The evolution of the German modal particle 'denn'. In Ilse Wischer \& Gabriele Diewald (eds.), New reflections on grammaticalization, 379-393. Amsterdam: Benjamins.

Weiß, Helmut. 2013. Satztyp und Dialekt. In Jörg Meibauer, Markus Steinbach \& Heidi Altmann (eds.), Satztypen des Deutschen, 763-784. Berlin \& New York: Walter de Gruyter.

Zifonun, Gisela, Ludger Hoffmann \& Bruno Strecker. 1997. Grammatik der deutschen Sprache. 3 Bände. Berlin: de Gruyter.

Zimmermann, Malte. 2008. Discourse particles in the left periphery. In Philippa Cook, Werner Frey, Claudia Maienborn \& Benjamin Shaer (eds.), Dislocated elements in discourse, 200231. Oxford: Routledge. 